\title{
EN TORNO A LA POLÉMICA HABERMAS-PUTNAM SOBRE LA VALIDEZ RACIONAL DE LOS JUICIOS ÉTICOS Y MORALES
}

\author{
Ricardo Navia \\ Universidad de la República/Uruguay
}

\begin{abstract}
If objectivity in scientific and empirical judgments is possible by the existence of independent entities, what kind of facts could be the possible grounds for objectivity in ethicalmoral judgments? Both Putnam and Habermas hold that values could have certain objectivity that comes from an intersubjective recognition about evaluative standars for which we can find good reasons in the context of a particular lifestyle. However, for Habermas, in the situation of contemporary societies where the matter is how to regulate the conflicts and relationships between diverse groups with conflicting ideals, that is no longer sufficient validity. The objectives of this paper are: 1) Rebuild the basic arguments of this debate. 2) take a view on some of the points in question, indicating a way to integrate aspects of both views, which I think could get the goal they share, this is, to ground the possibility of a cognitivist ethics that circumvents the problems of relativism without falling into the difficulties of metaphysical realism.
\end{abstract}

Keywords: Objectivity, thick ethical concepts, fact-value entanglement.

Resumo: Se nos juízos científicos ou empíricos a objetividade é possível pela existência de entidades independentes, que tipo de fatos poderiam assegurar a objetividade de julgamentos ético-morais? Tanto para Habermas como para Putnam os valores éticos têm uma certa objetividade que emana do "reconhecimento intersubjetivo de standars de avaliação para os quais podemos encontrar boas razões" no contexto de um estilo de vida particular. No entanto, para Habermas, essa validade não é mais suficiente na situação das sociedades contemporâneas, onde é preciso regular os conflitos e as relações entre diversos grupos com ideais muitas vezes conflitantes. Os objetivos deste trabalho são: 1) reconstruir os argumentos básicos desta controversia 2) adotar uma concepção sobre alguns dos pontos em questão, indicando uma forma de integrar os aspectos de ambas as visões, à qual poderia chegar ao alvo que eles compartilham, a saber, fundar a possibilidade de uma ética cognitivista que contorna os problemas do relativismo sem cair nas dificuldades de realismo metafísico.

Palavras-chave: Objetividade, conceitos éticos densos, emaranhamento de fatos e valores. 


\section{Introducción}

Tanto Hilary Putnam como Jürgen Habermas son pensadores que se han destacado no solo por la relevancia y solidez de sus aportes sino también por la amplitud de sus intereses y de sus obras. Sin embargo, pese a esta enorme amplitud y relevancia, el tema de la posibilidad de la fundamentación racional de las estimaciones éticas y morales ha despertado en ambos un muy particular y permanente interés. Es quizás por ello que casi al final de sus carreras ambos se prestaron a una singular y sostenida polémica sobre el tema, que ya lleva casi tres intervenciones de cada lado.

El debate comenzó cuando Putnam pronunció su conferencia sobre "Valores y normas" durante un congreso en Fráncfort con motivo del septuagésimo cumpleaños de Habermas; se continuó con la respuesta de éste durante un Encuentro sobre la obra de Putnam y el pragmatismo que tuvo lugar en Munich un año después, ocasión en la cual Putnam presentó su réplica. La polémica tuvo una nueva ronda en noviembre de 2002, en un coloquio que se desarrolló en la Northwestern University de Estados Unidos bajo el tema: "Norms, Facts and Values. A discussion between H. Putnam and J. Habermas". Según mi información, estas dos últimas intervenciones no han sido aún publicadas.

Vale remarcar que el debate tiene toda la relevancia propia de un tema central de la ética y la filosofía política contemporáneas, pero además es especialmente significativo en lo argumentativo por cuanto se produce entre dos pensadores que coinciden en varios rasgos centrales de sus filosofías. A saber: el rechazo de ambos tanto al realismo metafísico como al relativismo, su afirmación de posiciones ético-cognitivistas, su interés por una racionalidad consecuente pero no cientificista, su intento de conciliar, de diversos modos, la tradición kantiana con la tradición pragmatista y con ciertos elementos de la filosofía del lenguaje, rasgos, todos ellos, que han ido acercando sus posiciones en varios aspectos desde comienzos de los 90. Con ese trasfondo en común, los puntos de discrepancia y sus respectivas argumentaciones diferenciales cobran máxima significación.

Es también destacable que estamos frente a una polémica bien típica de la filosofía contemporánea, incluso, yo diría, típica de la filosofía postwittgesteiniana, puesto que la tradición desde la antigüedad clásica siempre tendió a pensar que el mero hecho de las discrepancias y pluralismos valorativos era un argumento suficiente para dudar radicalmente de toda posible objetividad de los enunciados estimativos. También es un tema 
típicamente contemporáneo porque como bien lo han señalado ambos autores, la Ilustración nos legó el problema de cómo compatibilizar la defensa de la tolerancia frente al pluralismo de costumbres, de creencias religiosas, de manifestaciones artísticas, de creencias políticas, etc., a la par de afirmar la necesidad y la pretensión de validez universal para esa misma tolerancia y otros derechos y procedimientos básicos que la acompañan y la posibilitan desde el siglo XIX. (Estado de derecho, democracia, etc.)

\section{La problemática en cuestión}

El tema central de la discusión es la posibilidad de formular y justificar enunciados objetivos sobre normas y valores, o, como dicen Vega y Gil: "cómo entender el sentido cognitivo de los enunciados de valor". Sobretodo en el contexto de sociedades democráticas contemporáneas caracterizadas por el "hecho del pluralismo" (Rawls), que incluyen concepciones sobre el bien muy diversas e incluso contradictorias entre sí.

La presencia de esos desacuerdos inconciliables, ¿inviabiliza la posibilidad de lograr objetividad en los juicios estimativos? Un argumento del escepticismo antiguo sostenía que: dado que para admitir algo como un hecho objetivo se requiere que sea reconocido más allá de divergencias, entonces en los dominios de lo estimativo donde impera el pluralismo, no habría posibilidad de enunciados objetivos e incluso el relativismo se tornaría inevitable.

Sin embargo, tanto Habermas como Putnam, sostienen que el pluralismo ético de hecho no quita la posibilidad de justificar la objetividad de los juicios de valor, aunque - y aquí nace la polémica - ambos fundamentan tal posibilidad de distintos modos.

Un aspecto fundamental de este debate está constituido por el modo en que ambos visualizan la relación entre la objetividad de los juicios científicos y empíricos y la objetividad de los juicios de valor. Si en los juicios empíricos la objetividad está posibilitada por la existencia de entidades independientes, ¿qué tipo de hechos serían los que podrían posibilitar la objetividad de los juicios ético-morales? El espectro de la postulación de entidades especiales, que daría lugar a algún tipo de realismo metafísico, comienza a acechar con esta cuestión. En el otro extremo, las concepciones naturalistas y positivistas, que intentan no recurrir a entidades o propiedades no directamente derivadas o postuladas por las explicaciones 
científicas, se niegan a concebir ningún tipo de hecho normativo independiente del accionar valorativo de los propios sujetos.

Por su parte, las posiciones no-cognitivistas sostienen que los enunciados evaluativos y normativos, pese a su apariencia asertórica, en realidad no expresan proposiciones que podamos catalogar como verdaderas o falsas y, por tanto, no pueden aspirar a ningún tipo de objetividad.

\section{Trasfondo común}

Frente a este cuadro de problemas, nuestros dos autores, van a sostener algunas posiciones en común que conviene reseñar antes de dibujar sobre ellas los argumentos diferenciales. Seguimos en esta parte la presentación que hacen Vega y Gil en la Introducción a la versión española de los tres primeros textos de la polémica ${ }^{1}$.

1 - Tanto Putnam como Habermas rechazan las posiciones nocognitivistas, a partir de que en base a argumentos de tipo pragmatista, se oponen a la equiparación de la objetividad de los enunciados normativos con la de los enunciados empíricos y científicos. Van a concebir la posibilidad de que la objetividad de los enunciados valorativos pueda estar basada no en la contrastación con hechos independientes sino en cierto tipo de razones.

2 - Ambos rechazan una ontología realista que postule la existencia de entidades o cualidades no naturales que se supone que serían captables por algún tipo especial de facultad (intuición axiológica) que serviría para definir la corrección o incorrección de los enunciados valorativos.

3 - Por último, ambos rechazan "la ontología deflacionaria de cierto realismo reductivo" 2 que sostiene que las propiedades a que refieren nuestros lenguajes normativos no son propiedades o conceptos con un estatuto propio sino que, más allá de la aparente especificidad, son propiedades naturales y por tanto los enunciados son reductibles a un lenguaje naturalista.

4 - A partir de que tanto Putnam como Habermas comparten aspectos básicos del llamado "giro pragmatista", Habermas y Putnam rechazan ciertas concepciones tradicionales sobre la objetividad, la representación y la racionalidad y por tanto, ya no van a concebir la

\footnotetext{
1 VEGA ENCABO, J. y GIL MARTÍN, J., "Introducción: Pragmatismo, objetividad normativa y pluralismo". In: PUTNAM, H. \& HABERMAS, J. Normas y valores. Madrid: Ed. Trotta, 2008.

2 Idem, p. 16.
} 
objetividad a partir de una imagen del conocimiento como una representación de una realidad independiente del lenguaje; sino que, dada la interpenetración entre lenguaje y mundo, las pretensiones cognitivas de nuestros enunciados remiten más bien a entendimientos intersubjetivos en el seno de una determinada comunidad.

Otros rasgos en común entre nuestros dos autores pueden rastrearse en Verdad y Justificación, obra de Habermas del mismo año en que se abre la polémica (1999).

Allí, Habermas plantea sus críticas a Rorty desde una posición que él cataloga como "pragmatismo kantiano", cuyos aspectos centrales dice compartir con Putnam. Continuamos entonces la enumeración de posiciones compartidas.

5 - En ambos las condiciones trascendentales para el conocimiento de los objetos no vienen dadas por estructuras subjetivas sino por la primacía de las prácticas de los seres capaces de acción y de lenguaje. Las condiciones de posibilidad ya no se encarnan en un sujeto atemporal e inmutable sino en prácticas lingüísticas y en formas de vida socioculturales.

Sin embargo, tanto para Putnam como para Habermas el desarrollo de esa experiencia consigue exceder los límites de las condiciones contextuales de la justificación al interior de los juegos del lenguaje. Escribe Habermas: "La concepción destrascendentalizada de la espontaneidad creadora... es compatible... con la expectativa de descubrir rasgos trascendentales universalmente extendidos que caractericen la constitución de las formas socioculturales de vida en general”3. Por su parte Putnam en su célebre ensayo Porqué la razón no puede ser naturalizada, sostiene que la razón es en parte inmanente y en parte trascendente al contexto, lo cual se manifiesta en la posibilidad de crítica pluscontextual que se evidencia en los cambios de paradigma. (Why reason can't be...).

6 - Una última idea enlaza el kantismo wittgensteiniano de Putnam con el pragmatismo kantiano de Habermas: la prioridad de la práctica y de la perspectiva de la primera persona. Dado el carácter esencialmente normativo de nuestras prácticas (incluyendo las de justificar enunciados) es necesario ubicarse en la lógica interna de un juego del lenguaje para comprender cómo se dan en el las condiciones de justificación.

${ }^{3}$ HABERMAS, J. Verdade e Justificação, p. 28. 


\section{Las posiciones básicas en el debate}

Los puntos de divergencia aparecen claros desde las dos primeras intervenciones.

Putnam va a comenzar señalando que es injustificada la distinción habermasiana entre normas y valores. Lo cual, a su vez, como para Habermas sólo las normas están regidas por el principio de universalización, trae además dos consecuencias negativas relevantes: deja a los valores en el campo de lo no cognitivo y, con ello, no da un sentido compartido al vocabulario evaluativo que es el que proporciona contenido a las normas que intenta privilegiar.

Por su parte, Habermas va a criticar a Putnam por su intento de validación racional de los valores en una modalidad de validación prácticamente igual a la de los enunciados empíricos que, según él, conduce a Putnam a un realismo de los valores que ambos intentaban evitar; frente a todo lo cual, Habermas reivindica la distinción kantiana entre razón teórica y razón práctica.

\section{Objetivos de este trabajo}

En este contexto polémico, los objetivos de esta exposición son:

1 - Reconstruir los argumentos básicos de la polémica

2 - Pronunciarme sobre algunos de los puntos en cuestión, indicando una forma de integrar aspectos de ambas visiones, que estimo podría conseguir con menos dificultades el objetivo que ambos comparten, de fundamentar la posibilidad de una ética cognitivista que eluda los problemas del relativismo sin recaer en las dificultades del realismo metafísico.

3 - Señalar algunos aportes al tema de la posición de Putnam que, en mi opinión, no han sido suficientemente realzados, ni siquiera en las propias intervenciones del autor.

\section{Los argumentos básicos de la polémica}

\section{La posición básica de Habermas}

Habermas establece una neta distinción entre normas morales y valores éticos. Sobre las normas sostiene que son universalmente válidas, en 
tanto de los valores considera que sólo son una expresión de preferencias limitadas a un contexto sociocultural.

Para él las normas morales están justificadas por el principio de universalización y apuntan básicamente a lograr la justicia, en tanto los valores dependen de la concepción que la comunidad tenga de la vida buena. En relación a las normas, el principio $\mathrm{U}$, a su vez, está procedimentalmente controlado en la medida en que para Habermas "cada norma válida ha de satisfacer la condición de que las consecuencias y efectos secundarios que se siguen de su acatamiento general para los intereses de cada persona... puedan ser aceptados por todos los afectados..." 4 , bajo las condiciones ideales de comunicación, la que a su vez está enraizada en los presupuestos pragmáticos de la argumentación en general. (Idem, p. 97).

Estos mismos presupuestos normativos del discurso prefiguran según Habermas la idea de un mundo plenamente inclusivo y esta idea opera como un referente dentro del discurso moral, como una instancia análoga a la indisponibilidad del mundo objetivo.

Para Habermas, a diferencia de las pretensiones de verdad del discurso empírico cuya verdad depende en cierto modo de la contrastación con objetos o hechos independientes, la corrección de las normas morales depende exclusivamente de la aceptabilidad racional de un discurso guiado por la idea de la inclusión universal de sus participantes (reales o potenciales), o sea, puede ser evaluada en términos exclusivamente epistémicos y excluye todo referente ontológico.

De ese modo, Habermas sostiene un cognitivismo fuerte con respecto a las normas morales. Sin embargo, si pasamos a los valores éticos, él va a sostener allí solo un cognitivismo débil. Los valores forman parte de la pluralidad de los mundos de la vida (contextos socio-culturales); su objetividad se funda en que tienen el reconocimiento intersubjetivo de esa comunidad.

\section{Posición de Putnam}

Putnam parte de considerar la tesis habermasiana que distingue claramente entre normas morales y valores éticos Como ya vimos, Habermas

\footnotetext{
${ }^{4}$ HABERMAS, J. "Ética del discurso. Notas sobre un programa de fundamentación". In: Conciencia moral y acción comunicativa. Madrid: Ed. Península, p.86.
} 
sostiene que solo las normas son universalmente válidas, en tanto de los valores considera que son una expresión de preferencias limitadas a un contexto sociocultural.

Frente a ello, la tesis central de Putnam en este tema es que podemos justificar la objetividad de los valores y que, por tanto, la tesis habermasiana de que la única norma universalmente válida es la norma de la acción comunicativa, es excesiva e inconvenientemente restrictiva. Para defender esta posición Putnam se vale de dos argumentos básicos: el llamado argumento de los cómplices culpables y el argumento de la indispensabilidad.

Según el primero de estos argumentos, nuestra concepción del mundo está formada por enunciados en los que se entretejen inextricablemente elementos descriptivos y valorativos. Esto, que a veces se conoce como el argumento de los "cómplices culpables", aunque resulta más adecuada la denominación de Mc Dowell que la llama Tesis de la inseparabilidad ${ }^{5}$, apunta a que no solo los enunciados valorativos sino incluso los enunciados descriptivos de las ciencias presuponen valores. En el caso de las ciencias, son presupuestos valores epistémicos (simplicidad, coherencia, elegancia, alcance explicativo, etc.). "la ciencia - sostiene Putnam en "El colapso de la dicotomía hechos-valores" - presupone valores y esos valores (coherencia, simplicidad, etc.) están en el mismo barco que los valores éticos con respecto a la objetividad"6.

Ya este argumento está indicando que si reconocemos alguna clase de objetividad a los juicios descriptivos debemos hacer algo parecido con los juicios valorativos.

Por su parte, la primacía de la práctica y del punto de vista del agente, típica de la tradición pragmatista, conduce directamente al argumento de indispensabilidad según el cual la objetividad no se necesita apoyar en un cierto dominio de objetos, sino más bien en el reconocimiento de la función que esos enunciados cumplen en cierto juego de lenguaje, dando inteligibilidad a ciertos conceptos y prácticas del juego y legitimando con ello cierto esquema conceptual. Sólo si pretendemos ubicarnos en un punto de vista exterior, arquimedeano, podemos dejar de advertir el sentido cognitivo de esos enunciados y conceptos.

5 MC DOWELL, J. "Non-Cognitivism and Rule Following". In: Mind, Value, and Reality. Citado por PUTNAM, H. en Normas y valores, p. 56.

${ }_{6}^{6}$ PUTNAM, H. The Collapse... p. 4 (cit. por V.G., p. 23). 
En el ámbito ético, el argumento plantea que la inteligibilidad del juego del lenguaje moral solo es posible suponiendo que los enunciados morales son verdaderos o falsos, esto es, que son cognitivamente significativos. Con este argumento se confirma una nueva forma de entender la objetividad, una forma que permite comprender el sentido de un hecho tan básico como que las razones tengan autoridad para nosotros, esto es, una forma no preeminentemente ontológica sino lingüístico-trascendental, de entender tal autoridad.

$\mathrm{Si}$ a esto agregamos que también es normativa nuestra racionalidad epistémica, que a veces se quiere usar para justificar o cuestionar a los juicios evaluativos, se llega a que, por el contrario, este argumento aventajaría al clásico porque lograría una justificación que no fuera circular.

Por su parte, los argumentos que adoptan un punto de vista externo, y que concluyen negando la cognitividad y la objetividad del lenguaje moral, parten de la suposición de la irreductible dicotomía entre hechos y valores. Yo diría más bien, que suponen la identificación de criterio de objetividad con referente empírico, lo cual no es más que un supuesto.

Putnam observa además que la tesis restrictiva de Habermas conduce a un no cognitivismo de los valores.

\section{Respuesta de Habermas}

En su intervención ${ }^{7}$ Habermas comienza reseñando algunos puntos de coincidencia con Putnam que ya fueron señalados: la idea de la inmanencia y trascendencia de la razón, la idea de que no sólo la ciencia no agota todo lo que podemos conocer sino que se encuentra normativamente estructurada, el reconocimiento de términos valorativos densos que tienen apariencia y funcionamiento de términos descriptivos pero que ambos autores reconocen que son descriptivos y valorativos a la vez.

Sin embargo, a partir del parágrafo (7) de su conferencia Habermas pasa a criticar la parte de la propuesta de Putnam que no le resulta satisfactoria, que él engloba bajo la idea de la no "diferenciación entre los modos de validez de los juicios de hecho y los juicios de valor" ${ }^{\text {. Para ello }}$

\footnotetext{
7 HABERMAS, J. "Un comentario al pragmatismo kantiano de H. Putnam". In: Habermas y Putnam, Normas y valores, p. 79 - 106.

8 Idem, p. 94.
} 
identifica tres argumentos de Putnam que se propone analizar y rebatir: 1) el solapamiento de valores cognitivos y valores no cognitivos, 2) el parentesco entre el pluralismo de las teorías y el pluralismo de las visiones del mundo y 3) la evaluación transcultural de prácticas y condiciones sociales.

1. Respecto al primer argumento dice que "Putnam concibe la base de valores de la investigación como un dato concluyente de que no hay una determinación valorativamente neutral de los hechos en la ciencia, como tampoco la hay en la ética o cualquier otro ámbito del saber"9. Pero, replica Habermas: "este primer paso puede desdramatizar la oposición entre el conocimiento empírico y el conocimiento ético únicamente si se puede demostrar que hay un continuo entre las orientaciones de valor cognitivas y las no cognitivas" 10 . Sin embargo, según Habermas, tal cosa no puede demostrarse pues "los valores cognitivos se caracterizan por su referencia funcional a la verdad" cosa que no se da en los otros casos. Como, a su vez, Habermas sabe que Putnam aduce que la verdad misma es un valor que se entreteje con otros valores, aclara que "no es la verdad como tal, sino el concepto epistémico de cerciorarse de la verdad lo que constituye la idea regulativa que guía nuestras prácticas de investigación"11.

Seguramente Putnam no accede a esta distinción por cuanto entiende - siguiendo la tradición pragmatista - que aún el objetivo de "perseguir la verdad” sin especificaciones es una idea vacía y darle contenido es lo que requiere ciertas opciones valorativas, con lo cual tendería a mantener la equiparación.

2. En relación al argumento de Putnam de que si bien hay pluralismo ético (de proyectos de vida y de "concepciones del bien") y no es dable esperar convergencia en esa área, algo análogo ocurre en el ámbito del conocimiento empírico; Habermas sostiene que si bien es cierto que no hay evidencia de convergencia en materia científica, sin embargo el propio Putnam ha argumentado contra la tesis de la inconmensurabilidad y a favor de ciertas evaluaciones transparadigmáticas, lo cual indicaría cierta tendencia convergente que se daría en el nivel moral. Mientras en el ámbito ético hay desacuerdos razonables que "hacen que cualquier intento ulterior de alcanzar

\footnotetext{
${ }^{9} / d e m$, p. 94.

10 Idem, p. 94.

11 Idem, p. 95.
} 
pese a todo un consenso sea absurdo"; en las cuestiones ético-existenciales las opciones diferenciales son esenciales y hacen que el conocimiento ético sea básicamente contextual y no pueda aspirar a validez universal.

En mi análisis, parece que Habermas más que erosionar la indistinción entre los modos de validez de los juicios de hecho y los juicios de valor, está si reafirmando la distinción normas/valores.

3 - Habermas señala que hay una ostensible contradicción entre dos ideas putnamianas. Por un lado, que "las formas de vida, las concepciones éticas... y las culturas se componen esencialmente de conceptos de valor "densos" ... de tal modo... que incluso las relaciones interpersonales reguladas legítimamente tan sólo pueden ser enjuiciadas desde perspectivas locales"12. En tanto, por otro lado el mismo Putnam sostiene que "conceptos abstractos como "bueno", “correcto", “deber" y "obligación” desempeñan el mismo papel gramatical en todos los lenguajes evaluativos" 13 , lo cual hace que, según Putnam, sea posible formular juicios de valor transcontextuales acerca de actos de otras culturas. (cita a Putnam, en ${ }^{14}$ ).

Para Habermas esa posibilidad diferencial precisamente está indicando la distinción que Putnam rechaza entre "una moral universalista de la justicia y una ética particularista del plan de vida.” E ilustra tal distinción apelando a un juicio transcultural que sabe que Putnam comparte porque lo ha manifestado muchas veces:

Llamamos cruel a la tortura de los seres humanos no sólo entre nosotros, sino en todo lugar. Pero de ningún modo nos sentimos justificados a protestar contra las prácticas educativas y las ceremonias matrimoniales que nos son extrañas ${ }^{15}$.

Como decíamos arriba, la preeminencia para Habermas de las normas morales sobre los valores éticos no significa que para este autor los valores sean arbitrarios o puramente subjetivos, por el contrario, los valores ostentan una cierta objetividad emanada del "reconocimiento intersubjetivo de estándares evaluativos para los cuales podemos encontrar buenas razones” (p. 98) en el contexto de una determinada forma de vida (cognitivismo débil).

\footnotetext{
12 Idem, p. 97.

13 Idem, p. 97.

14 PUTNAM, H. "Pragmatism and Relativism". In: Words and Life, p. 191.

${ }^{15}$ HABERMAS, J. "Un comentario al ...", p. 97.
} 
Muy distinta es la objetividad en sentido fuerte que ostentan "las cuestiones de justicia postradicional" donde "se ponen en juego estándares evaluativos que trascienden el contexto" de las comunidades particulares. En ese nivel de lo moral, "son correctos aquellos juicios que merecen reconocimiento universal, es decir que podrían encontrar el asentimiento de todas las personas afectadas dentro de un discurso racional conducido bajo condiciones aproximadamente ideales" (p. 99) ${ }^{16}$.

Para Habermas, los diversos tipos de enunciados se diferencian por el tipo de razones que son adecuadas en cada caso para justificarlos; y el tipo de razones marca el tipo de validez de los enunciados, el sentido ilocucionario con que se usan. Los juicios morales, igual que los juicios empíricos y matemáticos se caracterizan por una pretensión de validez universal y eso los distingue de los juicios de valor que no acceden a la aprobación universal sino solo el reconocimiento de quienes comparten ciertos estándares de valor de una cierta comunidad.

Habermas señala que Putnam al negarse a distinguir la validez veritativa de los enunciados empíricos y la validez deóntica de las obligaciones morales, procede a una equiparación entre valores particulares y normas universalmente vinculantes. Y el abandono de esta distinción quita fundamento a una concepción universalista de la moral que Putnam querría consolidar. Tal lo que ocurre al nivel de las comunidades relativamente aisladas, pero esta no es ya, según Habermas, la situación de las sociedades (o el mundo) contemporáneos, donde se trata de cómo regular los conflictos y las relaciones entre diversos colectivos con ideales muchas veces antagónicos. En las heterogéneas sociedades contemporáneas una regulación en el sentido de "los principios del universalismo igualitario, de los derechos humanos y la democracia" no puede seguir la lógica de las sociedades con un proyecto de vida y de bien común únicos y compartidos. Por todo ello, según Habermas es importante distinguir el nivel de las normas racionalmente universalizables del nivel de la coherencia evaluativa en una comunidad más o menos homogénea.

\section{Profundizando la posición de Putnam}

La parte central de la crítica de Putnam a la posición de Habermas consiste en cuatro puntos que podríamos sintetizar del siguiente modo:

16 Idem, p. 99. 
1 - Si se niega status cognitivo a los valores éticos y solo se lo reconoce a las normas morales de la Ética Discursiva (ED), esta última termina reducida a un minimalismo formalista con escasa capacidad de resolución de conflictos ético-morales y por su parte, los valores quedan relegados a un relativismo sociologista. En términos hegelianos sería una "moral carente de eticidad".

2 - La norma universal de la ED no puede ser la única norma universalmente válida porque para su propia formulación se requieren términos éticos densos

3 - Desde el momento en que nuestras normas universalizadas contienen términos éticos, "cualquier tipo de relativismo con respecto a los valores no puede dejar de afectar a las 'normas"' 17 .

4 - Para que la ED y la Situación Ideal de Habla (SIH) pudieran ser una condición no sólo necesaria sino también suficiente para producir verdades éticas, esta tendría que ser formulada con la ayuda de términos éticos densos.

Veamos algunos de estos argumentos con cierto detenimiento.

2 - Putnam sostiene que, a pesar de que él comparte la Ética del Discurso de Habermas, la norma universal de ésta no puede ser la única norma universalmente válida. Para empezar porque ella requiere de otros términos que, por ejemplo, sirvan para distinguir un cumplimiento sincero de un mero cumplimiento formal de dichas normas y dichos términos provienen de nuestra terminología ética básica.

Precisamente Putnam va a hacer hincapié en términos como "sincero" que efectivamente necesitamos para formular y aplicar las normas universales. Para él, en la tradición filosófica y en el no cognitivismo contemporáneo (Carnap, Reichenbach, Stevenson) se consideró que todas las expresiones éticas necesariamente contenían palabras éticas abstractas como bueno, malo, correcto, debería, etc.. Sin embargo, sostiene, sobretodo a partir del trabajo de Iris Murdoch ${ }^{18}$, se constató que también se pueden formular juicios de valor sin emplear dichas palabras, sino usando otros términos que tienen apariencia descriptiva pero encierra también una carga valorativa, como por ejemplo: cruel, sensible, refinado, vulgar, espontáneo impostado,

\footnotetext{
${ }^{17}$ La misma expresión aparece en PUTNAM, H. Normas y valores. p. 60 y en Respuesta a J. Habermas, p. 110.

${ }^{18}$ MURDOCH, I. The Sovereignity of Good. London: Routledge and Kegan Paul, 1970, p. 17 ss.
} 
agradable/desagradable, etc..a los cuales se les ha dado en llamar "términos éticos densos".

Lo más relevante en relación a estos términos es que en ellos lo descriptivo no se puede desligar de lo valorativo; ni tampoco, como suponía la psicología de las facultades, se puede distinguir una parte proveniente de la percepción que sería neutra, y otra proveniente de la voluntad que sería la que pone el valor. Por el contrario, son actitudes irreductibles que se adquieren en un cierto contexto cultural.

3 - Otra crítica que va a formular Putnam es que: desde el momento en que nuestras normas universalizadas contienen términos éticos, "cualquier tipo de relativismo con respecto a los valores no puede dejar de afectar a las 'normas"'19.

\section{Pasa luego a analizar posible réplicas de Habermas.}

1 - Plantea que si la ética del discurso es universalmente aplicable entones tiene que presuponer que los términos éticos involucrados, p. ej.: "castidad", tienen una forma de ser entendidos por otras comunidades para ser cognitivamente significativos; pero, si esto es el caso, entonces dichos términos no tienen que tener el acotamiento contextual con que Habermas los concebía.

2 - Antes de la Teoría de la Acción Comunicativa Habermas defendió la Ética Discursiva con la ayuda de la pragmática trascendental de Apel., quien siguiendo a Peirce sostenía que "la verdad se equipara a lo que se acordaría en el límite de una discusión indefinidamente continuada” (p. 62). A partir de lo cual, si hay verdad en una discusión ética, entonces al cabo de una discusión suficientemente prolongada se debe llegar a una convergencia.

Pero esto último para Putnam es claramente inaceptable, por varias razones:

A - Para empezar las normas que rigen la SIH no pueden ellas mismas justificarse por una discusión en SIH (PUTNAM, Valores y normas, p. 67).

B - Pero, sobretodo: aun cuando esos fueran condiciones necesarias para encontrar la verdad luego Apel-Habermas deberían demostrar que son

\footnotetext{
19 Idem, p. 60.
} 
condiciones suficientes para que el resultado de una tal discusión en temas éticos sea inevitablemente correcto (p. 67).

C - Además de la falta de claridad en el enunciado contrafáctico "suficiente o indefinidamente prolongado". Putnam quiere demostrar que "no hay razón para creer que el resultado de una discusión ideal y suficientemente prolongada de una cuestión ética sea inevitablemente correcto.” (p. 67). Pone el ejemplo de una discusión sobre si una acción X es cruel o no lo es. Supongamos que una mayoría, llevando adelante una discusión prolongada respetando los requisitos de una SIH llega a la convicción de que $\mathrm{X}$ no es una acción cruel (cuando en realidad lo es). Lo incorrecto ahí, dice Putnam, no es que no obedezcan las normas de la ED; sino que podría estar ocurriendo que esas personas tuvieran una cierta propensión al sadismo. Lo cual estaría indicando que: no toda SIH arriba a conclusiones verdaderas; sino que para que lo haga habría que agregar condiciones como que los participantes tengan un perfil sicológico determinado ${ }^{20}$, cierta sensibilidad media, etc. Luego, otro tanto puede ocurrir con sus capacidades imaginativas, su imparcialidad, etc. La cuestión es entonces, para Putnam, que las condiciones para que la SIH se acerque a resoluciones correctas solo se logran capturar en términos éticos densos, por tanto, estos no pueden tener una validez tan acotada como la que Habermas les atribuye.

Por otro lado, es atendible la observación de que, aún la ED reconoce la existencia de distorsiones sistemáticas en la discusión y para evitar tal "distorsión sistemática" sería necesario formular requisitos adicionales (sobre cómo evitar tales errores sistemáticos) y estos requisitos nuevamente no podrían expresarse sin apelar a términos densos.

Supongo, sin embargo, que este último argumento es muy caro a Habermas porque es especialmente relevante en la genealogía marxista de la Teoría Crítica que hace hincapié en las distorsiones sistemáticas que por efecto de la ideología dominante sufrimos en la percepción de los intereses no sólo de los otros sino de nosotros mismos; y, en ese sentido, se parece mucho a uno de los argumentos centrales que el mismo Habermas esgrimió contra Gadamer y a favor de lo que llamó hermenéutica crítica.

20 Putnam menciona que Habermas en la Teoría de la Acción Comunicativa (TAC) habla de que los participantes en la SIH "han logrado el equivalente de un psicoanálisis ideal" y cita TAC, trad., vol 2, p.153. 
Estimamos que con todo ello, Putnam logra mostrar que: así como la filosofía postempirista demostró que la ciencia no puede funcionar sin valores epistémicos irreductibles (coherencia, simplicidad, plausibilidad, etc.), la misma filosofía puede demostrar que el pensamiento ético-moral no puede funcionar sin valores éticos irreductibles.

En síntesis, a nuestro entender Putnam consigue mostrar la indispensabilidad y la irreductibilidad de los valores éticos en nuestros discursos prácticos. Pero no vemos que proporcione argumentos para mostrar que esos valores tengan una verdad más allá del contexto, como sí lo insinúa (en final de $O p$. cit. p. 72).

Lo que sí parece más atendible es que con estos argumentos ha mostrado que son las demandas que nos plantean estos valores, las que llenan de contenido a la ética kantiana o a la ED.

\section{Conclusiones}

1 - Creo que en primer lugar cabría descartar dos críticas duras que ambos pensadores se intercambian respectivamente y que, a mi entender, las dos parecen injustificadas. Por un lado, no parece que, como sostiene Putnam, Habermas sea un no-cognitivista en ética y por otro lado, no parece justificado sostener, como Habermas lo hace, que Putnam sea un realista metafísico de los valores. Veamos:

a - Habermas es un cognitivista en ética, no sólo porque así lo declara en su intervención (p. 98), sino sobretodo porque según su concepción hay posibilidad de fundar sus enunciados desde que se basan en razones apoyadas en pautas evaluativas suprapersonales (compartidas). Aunque luego él insista en que ese reconocimiento tiene un acotamiento contextual, por lo cual esos juicios evaluativos no tienen la obligatoriedad universal que solo emana de una razón inclusiva y universalizante como la que funda a las normas morales.

b - En cuanto al supuesto realismo metafísico de los valores en Putnam: no parece seguirse - como Habermas sostiene - que Putnam sea un realista ético duro o metafísico, en el sentido de postular entidades especiales que hicieran de referencia para dichos juicios, (ni que lo moralmente correcto sea independiente de nuestros humanos veredictos, ni que sea transculturalmente idéntico). Bien por el contrario, Putnam establece que la corrección ética se limita a encontrar las mejores razones éticas y epistémicas 
(dada la interpenetración de valores), para ciertos actos en cierto contexto cultural.

Pero precisamente la epistemología de Putnam pretende pasar entre la Escila del verificacionismo y la Caribdis del realismo metafísico. Hablando de ética, él fija su interés en aquellos juicios cuya verdad no está más allá de nuestras capacidades de verificación y reconocimiento.

Para nuestro autor, a diferencia de los realistas tout court tipo Cristina Lafont o Davis ${ }^{21}$, lo que hace verdaderos a los juicios éticos no es su referencia a entidades o hechos trascendentes - lo cual significaría una recaída en el realismo metafísico - sino el que los sujetos involucrados puedan manejar razones objetivas en el sentido de independientes de los juicios de los sujetos aislados. Ya en Ethics without Ontology2 Putnam había señalado que podemos hablar de "objetividad sin objetos" en el caso de las verdades éticas y morales, como al fin y al cabo, también lo hacemos en las verdades de la lógica y de la matemáticas.

De tal modo que la objetividad evaluativa según Putnam no emana solo de un acuerdo cultural suprapersonal sino también de una sintonía de fondo entre valores epistémicos y éticos en una comunidad.

2 - Mi segunda conclusión general se inclina a favor de la forma en que Habermas distingue entre valores y normas.

Habermas insiste en que en las cuestiones ético-existenciales las opciones diferenciales son esenciales y hacen que el conocimiento ético sea básicamente contextual y no pueda aspirar - al menos en principio - a validez universal.

Por otro lado, Putnam, sostiene que es posible formular juicios de valor transcontextuales acerca de actos de otras culturas. (cita a Putnam, $e^{23}$ ). Creo que como bien lo señala Habermas esa posibilidad precisamente está indicando la distinción que Putnam rechaza entre "una moral universalista de la justicia y una ética particularista del plan de vida."

Dicho de otro modo, como ambos sostienen, los valores ostentan una cierta objetividad emanada del "reconocimiento intersubjetivo de estándares evaluativos para los cuales podemos encontrar buenas razones” (NV p. 98) en

${ }^{21}$ LAFONT, C., "Realismo y constructivismo en la teoría moral kantiana - el ejemplo de la Ética del Discurso". In: Isegoría, 27, 2002; DAVIS, F., "Discourse Ethics and Ethical Realism: A Realist Realignment of Discourse Ehtics". In: European Journal of Philosophy, 2, 1994, p. 125-141.

22 PUTNAM, H. Ethics without Ontology. Cambridge: Harvard University Press, 2004.

23 PUTNAM, H. "Pragmatism and Relativism". In: Words and Life, p. 191. 
el contexto de una determinada forma de vida, pero ésta no es ya, como advierte Habermas, la situación de las sociedades (o el mundo) contemporáneos, donde se trata de cómo regular los conflictos y las relaciones entre diversos colectivos con ideales muchas veces antagónicos.

En las heterogéneas sociedades contemporáneas una regulación en el sentido de "los principios del universalismo igualitario, de los derechos humanos y la democracia" no puede seguir la lógica de las sociedades con un proyecto de vida y de bien común únicos y compartidos. Por todo ello, parece adecuado seguir a Habermas en la importancia de distinguir el nivel de las normas racionalmente universalizables del nivel de la coherencia evaluativa en una comunidad más o menos homogénea.

3 - Considero especialmente importante la concepción desarrollada por Putnam, sobre todo en "Razón, verdad e historia" de que, en aplicación de su tesis de la imbricación entre valores éticos y epistémicos, existe a las espaldas de cada cultura una cierta relación entre los valores éticos que resulta razonable defender y los valores epistémicos que se han ido asentando en el desarrollo cognoscitivo de dicha totalidad. Porque además es esta tesis la que permite explicar el surgimiento de una ética univesalizante e inclusiva en cierto momento del desarrollo conjunto de los valores éticos y epistémicos.

4 - Un aspecto importante en la concepción de Putnam que en estas intervenciones no termina de quedar claro es el de cómo sería posible según él que al menos algunos de esos juicios evaluativos puedan tener valor transcultural. Esto en principio parece intrínsecamente imposible desde que por su propia concepción los valores éticos tienen dependencia cultural y por tanto hay múltiples sistemas éticos. ¿Por qué alguno de ellos podría tener aspiraciones de evaluación transcultural? Procurando evitar el relativismo recaeríamos en un universalismo etnocéntrico peligrosamente dogmático. Creo que la forma de explicarlo para algunos casos podría ser introducir la dimensión histórica y sostener que: pueden tener legítima aspiración transcultural sólo aquellos juicios éticos densos que se generan en culturas que aprenden a convivir con la heterogeneidad, o, mejor dicho, cuyo desarrollo ético y epistémico es el resultado de un proceso cognitivodiscursivo a partir de la heterogeneidad, lo que equivale a decir que han llegado al principio U.; con lo cual estos juicios evaluativos son ya prácticamente normas morales universalizadas. 
De hecho, una ética discursiva como ética universalizante capaz de arbitrar la convivencia intercultural o en situación de multi-culturalidad al interior de una sociedad, no surge cuando meramente "descubrimos" las implicaciones pragmáticas inclusivas de la argumentación (aspecto formal) sino cuando además dicha sociedad va llegando a acuñar juicios y sistemas evaluativos de contenido inclusivo y por tanto universalizables.

4 - Si, por último cruzamos la ED con la tesis putnamiana de la correlación entre valores éticos y epistémicos, la ED como ética racional universalista aparecería como el correlato de una racionalidad cognitivo filosófica que ha descubierto las falencias tanto del dogmatismo particularista como del relativismo radical y por tanto busca procedimientos que le permitan continuar la búsqueda del bien y del conocimiento sin afirmar dogmáticamente ninguna posición pero también sin dejar de lado ciertos procedimientos mínimos que le permiten salvaguardar la pluralidad, el debate racional y con ello la construcción ética y cognitiva como un todo.

\section{Referências bibliográficas}

HABERMAS, J. "Ética del discurso. Notas sobre un programa de fundamentación". In: Conciencia moral y acción comunicativa, Ed. Península, Barcelona, 1985.

. Verdade e Justificação. São Paulo: Edições Loyola, 2004.

LÓPEZ DE LIZAGA, J. L. "Ética del discurso y realismo moral. El debate entre J. Habermas y C. Lafont”. In: Logos. Anales del Seminario de Metafisica, Madrid, vol. 41, 2008, p. 65-85.

PUTNAM, H., Ethics without Ontology. Cambridge: Harvard University Press, 2004.

. "Pragmatism and Relativism". In: Words and Life. Cambridge: Harvard University Press, 1995.

. "Pragmatism and Moral Objectivity". In: Words and Life. Cambridge: Harvard University Press, 1995.

. Razón, verdad e historia. Madrid: Tecnos, 1988.

. The Collapse of the Fact/Value Dichotomy. Cambridge: Harvard University Press, 2002.

. \& HABERMAS, J. Normas y valores. Introducción, traducción y notas de Jesús Vega Encabo y Javier Gil Martín. Madrid: Ed. Trotta, 2008. 
.W"hy reason can't be naturalized”. In: Philosophical Papers, vol. III, Realism and Reason. Cambridge: Cambridge Univ. Press, 1983.

- “Bernard Williams y la concepción absoluta del mundo". In:

Cómo renovar la filosofia. Madrid: Cátedra, 1994.

RAMÍREZ CALLE, O. "La pregunta por la verdad de los enunciados morales y la búsqueda de una fundamentación realista de la moral". In: Episteme NS, vol. $28, n^{-a} 1,2008$, p. 89-114. 